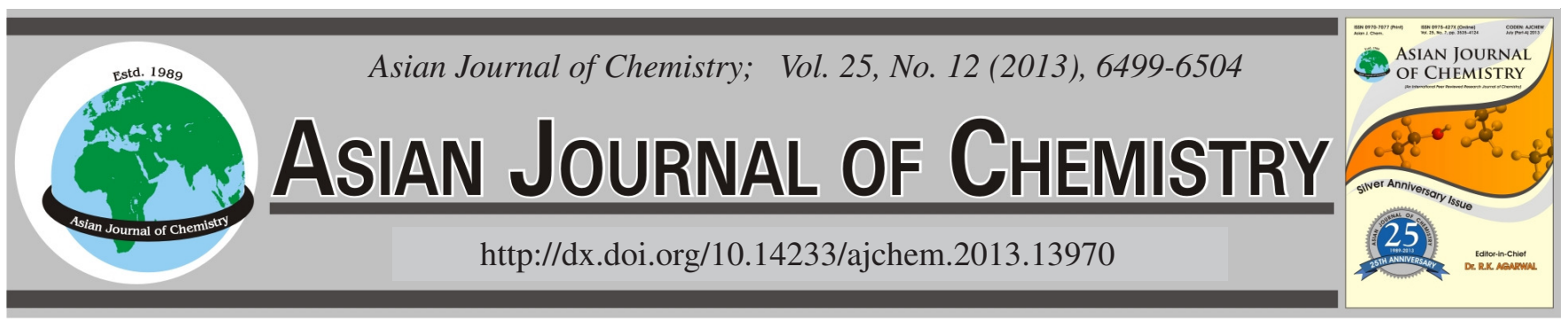

\title{
Influences of Sample Collection and Pre-Treatment on Lithium Assay with Ion Selective Electrode Method
}

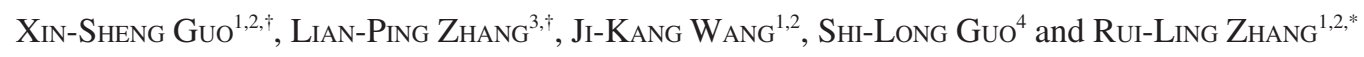

${ }^{1}$ The Second Affiliated Hospital of Xinxiang Medical University, No. 388 Jianshe Road, Xinxiang 453002, P.R. China

${ }^{2}$ Henan Key Laboratory of Bio-Psychiatry, Xinxiang, Henan Province, P.R. China

${ }^{3}$ Department of Urology, Second Xiangya Hospital, Central South University, Changsha 410011, P.R. China

${ }^{4}$ Pre-Medicine School of Xinxiang Medical University, Xinxiang, P.R. China

*Corresponding author: Fax: +86 373 3374082; E-mail: zhangruilingen@126.com

$\dagger$ These authors contributed equally to this work.

(Received: 27 April 2012;

Accepted: 17 May 2013)

AJC-13509

\begin{abstract}
The aim of this study was to explore the various pre-analytical influence factors on a sample's lithium measurement with the ion selection electrodes method. Eighty nine in-hospital patients who have taken lithium carbonic acid treatment were recruited. The blood samples were collected under different conditions to compare the lithium concentration difference which was determined with an Eashlyte ${ }^{\circledR}$ electrolyte analyzer. Lithium in samples collected at different time periods varied at the range from minimum $0.47 \mathrm{mmol} / \mathrm{L}$ to maximum $1.20 \mathrm{mmol} / \mathrm{L}$. Lithium in samples with hemolysis, hyperlipemia and separation gel treatment were all higher than that in common sera. Lithium in whole blood was significantly higher than that in plasma and it diminished with a decrease of red blood cell number $(\mathrm{P}<0.05)$. Lithium in coagulant-treated samples and plasma had no significant difference with that in common sera $(P>0.05)$. In samples treated with different conditions, without clot separation, in all samples lithium increased $(\mathrm{P}<0.05-0.001)$ after being stored at room temperature. After serum separation, lithium in sera after being stored for $24 \mathrm{~h}$ was no different at room temperature than at $4{ }^{\circ} \mathrm{C}(\mathrm{P}>0.05)$. Lithium concentration assayed with the ion selection electrodes method was greatly impacted with the use of different sampling and pre-treatment methods.
\end{abstract}

Key Words: Lithium, Ion selective electrode, Sample collection, Pre-treatment.

\section{INTRODUCTION}

Lithium remains a first-choice mood stabilizer for preventing relapses in bipolar disorders ${ }^{1,2}$ and is also the only mood stabilizer for which a preventive effect on suicidal risk has been clearly shown ${ }^{2,3}$. With lithium treatment, suicidal risk could be reduced regardless of age or gender ${ }^{4}$. But a disadvantage of lithium is narrow therapeutic range $(0.4-1.5 \mathrm{mmol} /$ $\mathrm{L})$, its therapeutic and toxic doses are very close, the minimum toxicity was reported at level of $1.6 \mathrm{mmol} / \mathrm{L}^{5-7}$ sideeffects were observed on nearly all patients at the concentration of $2.0 \mathrm{mmol} / \mathrm{L}$. And interaction between different drugs or other factors could also result in increased or reduced lithium ${ }^{8,9}$ which brought a great deal of risk and inconvenience for the clinician to adopt lithium treatment. Therefore, a quick and accurate standardized lithium monitoring report was clinically required in order to prevent any toxic reactions after a therapeutic dose ${ }^{10}$.

The reported lithium assay methods mainly included: flame photometry $(\mathrm{FP})^{11}$, atomic absorption spectrometry $(\mathrm{AAS})^{6,12}$ ion selective electrode (ISE) $)^{13}$, chromatometry ${ }^{14-16}$, differential pulse voltammetry ${ }^{17}$, reverse iontophoresis ${ }^{18}$, magnetic resonance spectrum (MRS) ${ }^{19}$, microchip capillary electrophoresis ${ }^{20}$, computer-aid prediction of lithium concentration $^{21}$, etc. Now, FP, AAS and ISEs are clinically utilized, among which ISEs has become the predominant method for measuring lithium in serum. Compared with FP and AAS, the influence from ISE samples on the result varies significantly $^{22,23}$. It was reported that the pre-analytical experiment error accounted for 32-75\% of total errors and blood sample preparation was the most important and immediate factor to determine the accuracy and reliability of clinical chemical analysis $^{24,25}$. Therefore, the sample collection and treatment played a very important role on lithium assay accuracy with ISEs. Several studies have reported ${ }^{26,27}$ on this, but we consider them incomprehensive. In this article, with ISEs method to determine lithium concentration, the pre-analytical influence factors were discussed in detail, such as: different sample collection time, food and drink, anticoagulant and hemolysis, hyperlipemia, different storage conditions, separation gel, coagulant and hematocrit.

\section{EXPERIMENTAL}

The lithium concentration was assayed with Eashlyte ${ }^{\circledR}$ electrolyte analyzer made by MEDICA, USA; the performance 
index of lithium analysis: sensitivity was $0.01 \mathrm{mmol} / \mathrm{L}$, measurable range was $0.0-5.0 \mathrm{mmol} / \mathrm{L}$; and with precision at level of $0.98 \mathrm{mmL} / \mathrm{L}$, the SD of within-batch and day-to-day were $\mathrm{SD}<0.03 \mathrm{mmol} / \mathrm{L}$ and $\mathrm{SD}<0.05 \mathrm{mmol} / \mathrm{L}$, respectively. And electronic analytical balance made by Precisa XT120A, Switzerland; Water purifier, Model: WaterPro PS/UF, made by Labconco, USA; Research pipette, made by Eppendorf, Germany; Centrifuge, model: Biofuge Stratos, made by Heraus, Germany.

The Eashlyte ${ }^{\circledR}$ dedicated calibration reagent/wash solutions were from MEDICA Corporation, USA. Calibration reagent Type A had: $\mathrm{Na}^{+} 140 \mathrm{mmol} / \mathrm{L}, \mathrm{K}^{+} 4.0 \mathrm{mmol} / \mathrm{L}, \mathrm{Cl}^{-}$ $125.0 \mathrm{mmol} / \mathrm{L}, \mathrm{Li}^{+} 1.00 \mathrm{mmol} / \mathrm{L}$; calibration reagent type $\mathrm{B}$ had: $\mathrm{Na}^{+} 35.0 \mathrm{mmol} / \mathrm{L}, \mathrm{K}^{+} 16.0 \mathrm{mmol} / \mathrm{L}, \mathrm{Cl}-41.0 \mathrm{mmol} / \mathrm{L} \mathrm{Li}^{+}$ $0.40 \mathrm{mmol} / \mathrm{L}$. Wash solution contained ammonium bifluoride of $0.1 \mathrm{mmol} / \mathrm{L}$.

Quality control (QC) substances: Home-made lithium quality control serum ${ }^{28}$ was prepared and quality control materials of $0.98 \mathrm{mmol} / \mathrm{L}(\mathrm{Lot} 437 \mathrm{UN}$ ) and $1.92 \mathrm{mmol} / \mathrm{L}$ (Lot 286UE) were purchased from RANDOX®. Strict internal quality control runs were conducted before the actual assays were performed.

Automatic vein hemostix: Four types of automatic vein hemostix (SANLI@, Hunan Liuyang Medical Instrument Factory, Hunan, China) were common (red colour), with separation gel (yellow colour), with heparin sodium (green colour) and with coagulant (jacinth colour), respectively.

Patient: All study participants were patients of Henan hospital who were being treated with lithium carbonate for bipolar or schizoaffective disorder. The patients have been receiving chronic lithium therapy at doses of 12-36 mmol/ day (carbonate salt) for no fewer than 3 weeks. Total 89 samples, 47 males and 42 females with age range of 18-65 years were included. This study was in compliance with the Declaration of Helsinki ethnical principles and had been approved by the Second Affiliated Hospital of Xinxiang Medical University Ethnics Committee. All included patient had been informed in advance and written consent had been obtained.

Sample collection and treatment: The blood sample collections were accomplished by well-trained clinical nursing personnel, under the conditions of fasting (except the experiment of the influence of food and drink on lithium measurement), decubitus position and with vacuum automatic vein hemostix. All blood samples were collected at 7:00 am and sent to laboratory straight after collection to be assayed by the same laboratory technicians. Within the specified time, the blood samples were centrifuged for $10 \mathrm{~min}$ at a centrifugal force of $1000 \times \mathrm{g}$ to separate serum or plasma for analysis. To avoid any error from blood sampling, the sequence of blood sample collection was randomized. The blood samples were collected, treated and assayed between $20-26^{\circ} \mathrm{C}$.

Research method: The investigation was conducted studying a variety of pre-analytical influence factors on lithium concentration measurement with ISEs method, such as: different blood sample collection time, food and drink, hemolysis, hyperlipemia, different storage conditions $\left(4^{\circ} \mathrm{C}\right.$ and room temperature), anticoagulant, separation gel, coagulant and red blood cell (RBC) interference, etc. These would be elaborated in following result and discussion section. Once the test result was out of equipment detection range, the sample would be diluted with serum without lithium to do a 2nd assay and be calculated, the result was included into the final statistical analysis.

Statistical analysis: Auto-controlled design was applied for the whole study. Analysis was performed with SPSS for Windows (Ver. 12.0) statistical software (SPSS, Inc) and the results were expressed as Mean (SD). 1-Sample KolmogorovSmirnov test was utilized for distribution type analysis. Pairedsamples T test (2-tailed) was used to compare samples of each type (food and drink, anticoagulant, hemolysis, hyperlipemia, separation gel, coagulant and whole blood) with common ones. Univariate analysis of variance (LSD) was performed to evaluate the impact of RBC and storage time on lithium concentration. The assay results were analyzed with curve estimate, then with correlation analysis (r) and regression analysis (R), as well as plotting. P values $<0.05$ were considered statistically significant.

\section{RESULTS AND DISCUSSION}

Impact of different sample collection times on lithium concentration: One in-hospital patient was recruited voluntarily. When steady-state has been reached after lithium treatment, the patient's blood samples were collected within $24 \mathrm{~h}$ from 7:00 am to 7:00 am of next day; a total of 11 times. And lithium was assayed straight after collection. The lithium at different time periods varied greatly, ranging from Min $0.47 \mathrm{mmol} / \mathrm{L}$ to Max $1.20 \mathrm{mmol} / \mathrm{L}$, as illustrated in Fig. 1.

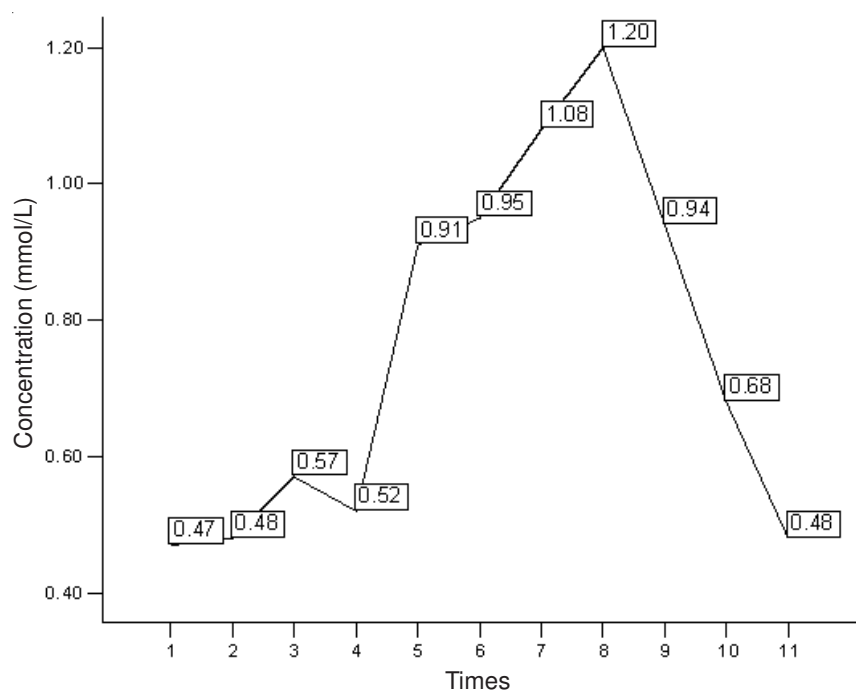

Fig. 1. Impact of different sample collection time on lithium the measured lithium concentration at different time frame showed big variation, ranging from minimum $0.47 \mathrm{mmol} / \mathrm{L}$ to maximum $1.20 \mathrm{mmol} / \mathrm{L}$

Fixed blood sampling time was suggested for the patient receiving chronic lithium therapy for monitoring. Generally, blood samples were drawn $12 \mathrm{~h}$ after intake of lithium ${ }^{29}$.

Impact of hemolysis on lithium concentration: After steady-state has been reached for one week in 13 in-hospital patients with lithium treatment, 2 blood samples were collected from each fasting patient in 2 tubes, one of which was randomly selected as Group\#1_(non-hemolytic samples), the rest were named Group\#2_(hemolytic samples). Group\#1 samples' sera were centrifuged and stored at room temperature. 


\begin{tabular}{|c|c|c|c|c|}
\hline \multicolumn{5}{|c|}{$\begin{array}{l}\text { TABLE-1 } \\
\text { LITHIUM CONCENTRATION COMPARISON AMONG DIFFERENT SAMPLES }\end{array}$} \\
\hline Sample type & Mean $(\mathrm{SD})^{\mathrm{a}}$ & $\mathrm{t}(\mathrm{P})^{\mathrm{b}}$ & $95 \% \mathrm{CI}^{\mathrm{c}}$ & $\mathrm{r}(\mathrm{P})$ \\
\hline $\begin{array}{l}\text { Hemolytic }(\mathrm{n}=13) \\
\text { Non-hemolytic }(\mathrm{n}=13)\end{array}$ & $\begin{array}{l}0.65(0.28) \\
0.61(0.27)\end{array}$ & $5.130(0.000)^{\mathrm{d}}$ & $0.03-0.07^{d}$ & $0.995(0.000)^{\mathrm{d}}$ \\
\hline $\begin{array}{l}\text { Fasting }(\mathrm{n}=13) \\
\text { Breakfast }(\mathrm{n}=13)\end{array}$ & $\begin{array}{l}0.61(0.26) \\
0.64(0.27)\end{array}$ & $2.134(0.054)^{\mathrm{e}}$ & & $0.976(0.000)^{\mathrm{e}}$ \\
\hline $\begin{array}{l}\text { Normal TG }(\mathrm{n}=10) \\
\text { Hyperlipemia }(\mathrm{n}=10)\end{array}$ & $\begin{array}{l}0.33(0.22) \\
0.35(0.24)\end{array}$ & $2.561(0.028)^{f}$ & $0.00-0.05^{\mathrm{f}}$ & $0.992(0.000)^{\mathrm{f}}$ \\
\hline $\begin{array}{l}\text { Serum }(\mathrm{n}=27) \\
\text { Plasma1 }(\mathrm{n}=27)\end{array}$ & $\begin{array}{l}0.62(0.21) \\
0.62(0.21)\end{array}$ & $0.044(0.965)^{\mathrm{g}}$ & & $0.995(0.000)^{\mathrm{g}}$ \\
\hline $\begin{array}{l}\text { Plasma2 }(\mathrm{n}=25) \\
\text { Whole blood }(\mathrm{n}=25)\end{array}$ & $\begin{array}{l}0.61(0.09) \\
0.68(0.06)\end{array}$ & $10.248(0.000)^{\mathrm{h}}$ & $0.05-0.07^{\mathrm{h}}$ & $0.979(0.004)^{\mathrm{h}}$ \\
\hline Common $(\mathrm{n}=14)$ & $0.64(0.14)$ & - & - & - \\
\hline Separation gel $(n=14)$ & $1.09(0.32)$ & $5.465(0.000)^{\mathrm{i}}$ & $0.28-0.64^{\mathrm{i}}$ & $0.288(0.318)^{\mathrm{I}}$ \\
\hline Coagulant $(n=14)$ & $0.64(0.16)$ & $0.452(0.659)^{\mathrm{j}}$ & - & $0.993(0.000)^{\mathrm{j}}$ \\
\hline
\end{tabular}

Group\#2 samples were refrigerated at $-20{ }^{\circ} \mathrm{C}$ without red blood cell separation which intentionally caused different extents of hemolysis. Then Group\#2 samples were centrifuged and assayed together with Group\#1 samples; lithium, hemoglobin $\mathrm{Hb}$ ) and potassium in the sera of samples were assayed, respectively.

The lithium in hemolytic samples was slightly higher than that in non-hemolytic samples $(\mathrm{P}=0.000)$. By curve estimate, lithium difference between hemolytic and non-hemolytic samples had no correlation with hemoglobin concentration or hemolysis-induced potassium concentration increase $(\mathrm{P}>$ 0.05), as summarized in Table-1 and illustrated in Fig. 2A. A previous study ${ }^{30}$ showed that lithium in blood plasma was about 2 -fold higher than that in red blood cells. The hemolysis was supposed to be able to reduce lithium concentration, however, increased lithium was observed in our study. The possible reason was that hemolysis induced a great number of releases of potassium from red cells into the serum, which resulted in the tremendous increase of potassium. And with any excessive increase of each kind of ion, the ISE result of other ions will get impacted.

Impact of food and drink on lithium concentration: After steady-state has been reached for one week in 13 fasting in-hospital patients with lithium treatment, vein blood was collected to do lithium assay at 8:30 am on day one. At 7:00 am on the next day, the patient took regular breakfast; at 8:30 am, the vein blood samples were collected again to do a 2 nd lithium assay. No significant difference was noted between these two lithium concentrations $(\mathrm{P}=0.054)$. The data were summarized in Table-1 and illustrated in Fig. 2B.

Impact of hyperlipemia on lithium concentration: The sera from 10 patients with lithium treatment were diluted with mixed-sera $(1: 1, \mathrm{v} / \mathrm{v} \%)$ which had triacylglycerol concentration of 0.6-1.7 mmol/L and 3.5-7.0 $\mathrm{mmol} / \mathrm{L}$, respectively. The lithium was assayed in the same batch. Lithium in hypertriacylglycerolemia case was higher than that in the normal case $(\mathrm{P}=0.028)$ as summarized in Table- 1 and illustrated in Fig. 2C.

Present study results indicated that lithium in serum from patients eating breakfast had no significant difference with that from a fasting patient. This might be related to the Chinesestyle breakfast which has mainly carbohydrates and less fat; whereas, lithium in serum with hypertriacylglycerolemia was a bit higher than the normal level. It was suggested that under the conditions of taking a Chinese-style breakfast, patient fasting or not, the blood samples could both be drawn for lithium assay; however, the test results would slightly increase in patients with excessive intake of fatty food or with a hyperlipemia condition.

Lithium concentration difference between serum and plasma: Blood samples were collected in common tubes and vacuum tubes with heparin sodium anticoagulant, respectively from 27 patients. Then lithium was assayed in the same batch. Lithium in plasma had no significant difference from that in serum $(\mathrm{P}=0.965)$, as summarized in Table- 1 and illustrated in Fig. 2D.

Fourteen samples were centrifuged without serum-separation and stored at room temperature for $8 \mathrm{~h}$ to get slightly higher result than that prior to storage (named as $0 \mathrm{~h}$ ), which was summarized in Table-2.

Lithium concentration difference between whole blood and plasma: Blood samples were collected in vacuum tubes with heparin sodium anticoagulant from 25 patients. Lithium was assayed in both whole blood and blood plasma. Lithium

TABLE-2

LITHIUM CONCENTRATION COMPARISON IN DIFFERENT SAMPLES AFTER $8 \mathrm{~h}$ STORAGE $(\mathrm{n}=14)$

\begin{tabular}{|c|c|c|c|c|}
\hline Sample type & $0 \mathrm{~h}$, Mean $(\mathrm{SD})^{\mathrm{a}}$ & $8 \mathrm{~h}$, Mean $(\mathrm{SD})^{\mathrm{a}}$ & $\mathrm{t}(\mathrm{P})^{\mathrm{b}}$ & $95 \% \mathrm{CI}^{\mathrm{c}}$ \\
\hline Common & $0.64(0.14)$ & $0.67(0.15)$ & $4.286(0.001)$ & $0.02-0.05$ \\
\hline Heparin anticoagulant & $0.63(0.14)$ & $0.66(0.17)$ & $2.400(0.032)$ & $0.00-0.05$ \\
\hline Separation gel & $1.09(0.32)$ & $11.45(6.03)$ & $6.635(0.000)$ & $6.99-13.74$ \\
\hline Coagulant & $0.63(0.16)$ & $0.68(0.18)$ & $2.818(0.015)$ & $0.02-0.08$ \\
\hline
\end{tabular}

${ }^{\mathrm{a}} 1$-Sample Kolmogorov-Smirnov test proved the data of each assay item were normal distribution, unit: $\mathrm{mmol} / \mathrm{L}$; ${ }^{\mathrm{b}} \mathrm{Paired}$-samples $\mathrm{T}$ test (2-tailed) was comparison between $8 \mathrm{~h}$ and $0 \mathrm{~h}$; ${ }^{c} 95 \% \mathrm{CI}$ was $95 \%$ confidence interval of the difference between $8 \mathrm{~h}$ and $0 \mathrm{~h}$, unit: $\mathrm{mmol} / \mathrm{L}$ 

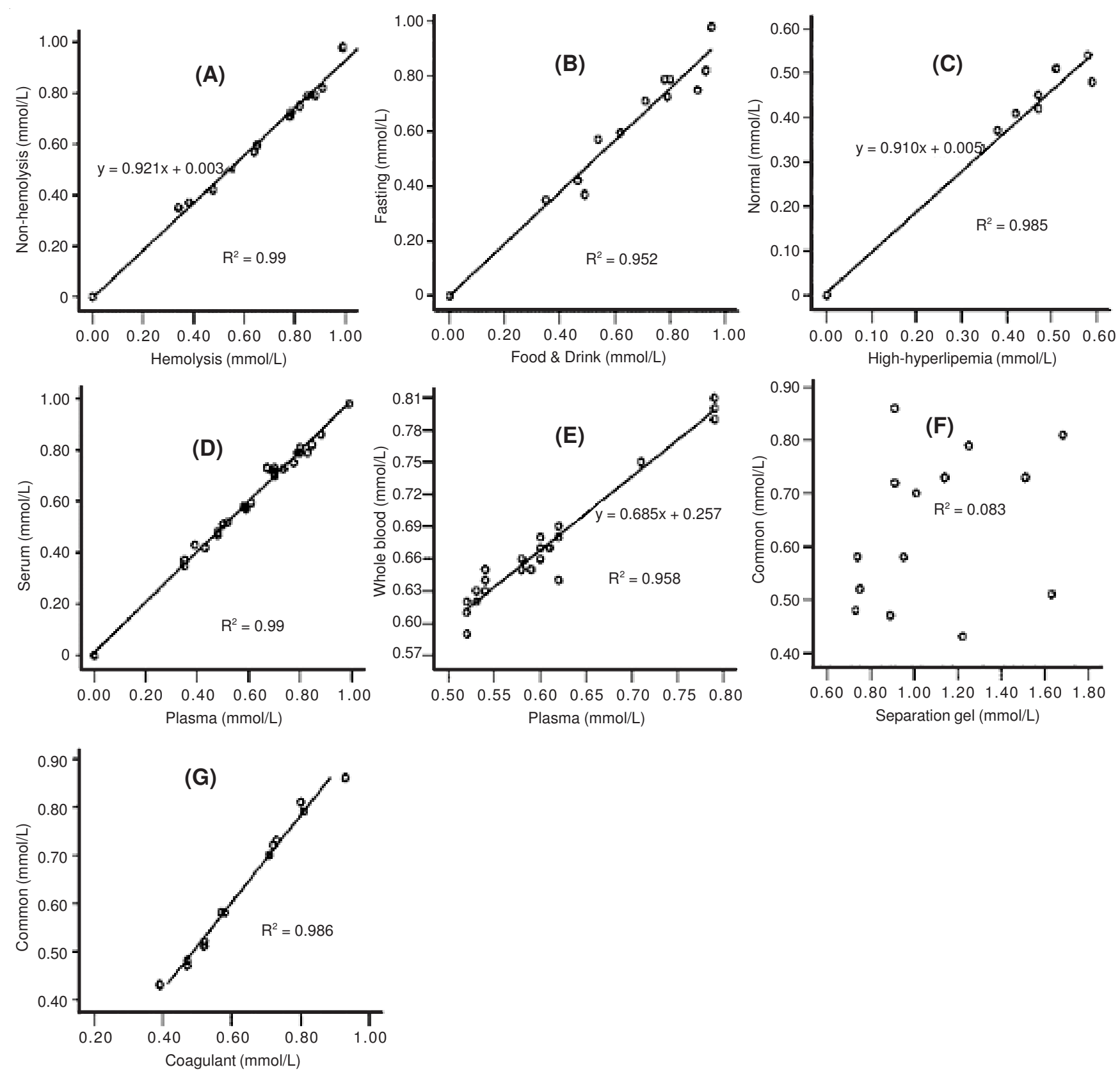

Fig. 2. Lithium concentration comparison among a variety of samples, (A) Hemolysis $v s$. non-hemolysis, Hemolytic samples were slightly higher, (B) Food \& drink vs. fasting. No significant difference, (C) hyperlipemia vs. normal. Hyperlipemia case was higher, (D) Plasma vs. serum. No significant difference, (E) Plasma vs. whole blood. Whole blood case was higher, (F) Separation gel vs. common. Separation gel case was much higher. No linear correlation, (G) Coagulant $v s$. common. No significant difference

in whole blood was higher than that in plasma $(\mathrm{P}=0.002)$, as summarized in Table-1 and illustrated in Fig. 2E.

Impact of RBC on lithium concentration in whole blood: Blood samples were collected in vacuum tubes with heparin sodium anticoagulant from 10 patients. Lithium was assayed in whole blood samples, which was followed by blood cell analysis. Then samples were centrifuged and a certain portion of red blood cells were discarded. After the sample remainder was fully mixed, the lithium and blood cell analysis were both assayed again. With the same procedure repeated 3 more times, the variation of each result and the association between lithium in whole blood and RBC/hematocrit (HCT) was obtained. Lithium diminished with the decrease of $\mathrm{RBC}$ /
HCT [Univariate analysis of variance (LSD), $\mathrm{F}=19.915, \mathrm{P}=$ 0.000]; linear association was observed among lithium concentrations with different HCT in whole blood samples $[\mathrm{r}=$ 0.996 for second and first tests; $r=0.993$ for third and first tests, $r=0.997$ for fourth and first tests $(\mathrm{P}=0.000$ for all $)$ ]. And lithium also was linearly associated with RBC/HCT, $(r=$ 0.989; $\mathrm{P}=0.011$ ), as summarized in Table-3 and Fig. 3.

The study results indicated that lithium in plasma had no significant difference with that in serum. The plasma could take the place of serum for lithium analysis purpose. And more convenient sample preparation was expected clinically by means of plasma assay for faster lithium analysis. However, present study showed that direct lithium assay in whole blood 


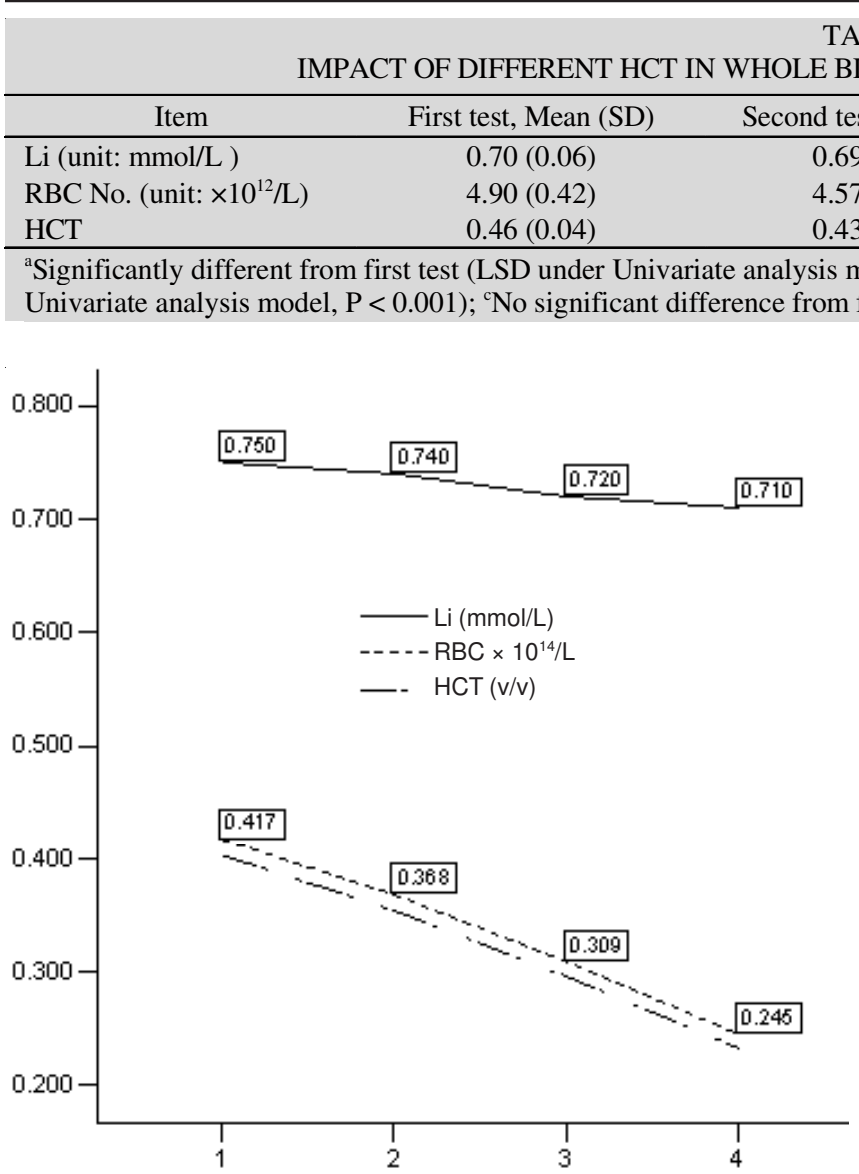

Fig. 3. Trends of lithium concentration and RBC. Llthium concentration reduced with the decrease of $\mathrm{RBC} / \mathrm{HCT}$

sample had significant difference with that in plasma $(\mathrm{P}<$ 0.001 ) and lithium diminished with the decrease of RBC or HCT $(\mathrm{P}<0.05-0.001)$. The RBC might interfere with the lithium measurement, so whole blood sample could not be used for direct lithium assay. The reason probably was that different junction potential was induced by the distribution of $\mathrm{RBC}$ with different HCT at the electrode membrane interface ${ }^{27}$ ) thus, the lithium ionic activity assay was interfered.

In non-separated clotted serum, the impact of different storage time on lithium concentration variation at room temperature: Vein blood was collected from 10 fasting patients, centrifuged within $0.5 \mathrm{~h}$ after collection, which was followed by lithium assay and the measured data was regarded as ' $0 \mathrm{~h}$ '. Then the samples were air-tightly stored at room temperature $\left(23 \pm 2{ }^{\circ} \mathrm{C}\right)$ and lithium was assayed at 3, 6 and $24 \mathrm{~h}$, respectively. The latter 3 data were all higher than the first one (Univariate analysis of variance, $\mathrm{F}=38.364, \mathrm{P}=$ $0.000)$, as summarized in Table- 2 .

After separation, the impact of different storage time at two types of temperature $\left(4^{\circ} \mathrm{C}\right.$ and room temperature) on lithium concentration in serum: Vein blood was collected from 10 fasting patients and processed serum separation within $0.5 \mathrm{~h}$ after collection, in which the lithium concentration was regarded as ' $0 \mathrm{~h}$ '. Then, the sera were kept air-tightly for 3, 6 and $24 \mathrm{~h}$ at room temperature and $4^{\circ} \mathrm{C}$, respectively. All lithium from the latter 3 groups had no significant difference from $0 \mathrm{~h}$ samples [per univariate analysis of variance, $\mathrm{F}=0.391(\mathrm{P}=$ 0.761 ) for $4{ }^{\circ} \mathrm{C} ; \mathrm{F}=0.402(\mathrm{P}=0.753$ ) for room temperature, respectively], as summarized in Table-4.

This study proved that after sample collection, if the serum could not be separated promptly, was stored at room temperature for $24 \mathrm{~h}$, the final result would increase. However, after serum separation, lithium in samples kept either at $4{ }^{\circ} \mathrm{C}$ or room temperature for $24 \mathrm{~h}$ had no significant difference. Therefore, once blood samples were drawn from patients, the assay had to be conducted immediately; if not available right away, the centrifuged samples had to be separated and sera had to be kept sealed.

Comparison of lithium concentration between with V.S. without separation gel treatment: Blood samples were collected from 14 patients in common tubes and tubes with separation gel, respectively. Lithium was assayed in same batch. Lithium in samples with separation gel was much higher than that in samples without separation gel $(\mathrm{P}=0.000)$, as summarized in Table-1 and illustrated in Fig. 2F.

After samples were treated with separation gel without serum separation, the lithium concentration difference between before and after being stored for $8 \mathrm{~h}$ at room temperature was investigated. Lithium in stored samples was more than 10fold higher than the former $(\mathrm{P}=0.000)$, as summarized in Table-2.

Some relevant studies ${ }^{26,31-33}$ had shown that separation gel had different effect on different assay items. Our study demonstrated that lithium had increased greatly with ISEs because of separation gel treatment. So, the sample could not be treated with separation gel for lithium assay; this was basically consistent with the report ${ }^{26}$. Furthermore, the lithium also increased with the extension of storage time. We submit that separation-gel-treated samples cannot be used for lithium assay with ISEs, neither for storage nor for shipping.

Lithium concentration comparison between with and without coagulant: Blood samples were collected from 14

LITHIUM CONCENTRATION COMPARISONLE-4

LITHIUM CONCENTRATION COMPARISON AMONG DIFFERENT STORAGE TIME $(\mathrm{n}=10)$

\begin{tabular}{lccccc}
\hline Sample type & Storage condition & $0 \mathrm{~h}$, Mean (SD) & 3 h, Mean (SD) & 6 h, Mean (SD) & $24 \mathrm{~h}, \mathrm{Mean}(\mathrm{SD})$ \\
\hline Non-separated clotted Sera (unit: mmol/L) & Room Temp & $0.67(0.15)$ & $0.72(0.16)^{\mathrm{b}}$ & $0.70(0.17)^{\mathrm{a}}$ & $0.74(0.15)^{\mathrm{b}}$ \\
\hline \multirow{2}{*}{ Separated clotted Sera (unit: mmol/L) } & $4^{\mathrm{o}} \mathrm{C}$ & $0.58(0.33)$ & $0.58(0.31)^{\mathrm{c}}$ & $0.56(0.30)^{\mathrm{c}}$ & $0.57(0.31)^{\mathrm{c}}$ \\
& Room Temp & $0.58(0.33)$ & $0.58(0.31)^{\mathrm{c}}$ & $0.57(0.32)^{\mathrm{c}}$ & $0.58(0.32)^{\mathrm{c}}$ \\
\hline
\end{tabular}

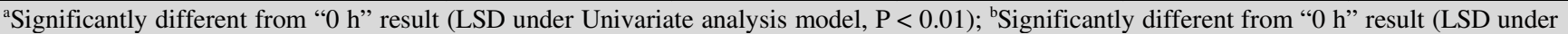
Univariate analysis model, $\mathrm{P}<0.001$ ); ${ }^{\circ}$ No significant difference from " $0 \mathrm{~h}$ " result (LSD under Univariate analysis model, $\mathrm{P}>0.05$ ). 
patients in common tubes and vacuum tubes with coagulant, respectively. Lithium was assayed in the same batch. Lithium in common sera had no significant difference from that in sera with coagulant $(\mathrm{P}=0.659)$, as summarized in Table-1 and illustrated in Fig. $2 \mathrm{G}$.

After samples were stored at room temperature for $8 \mathrm{~h}$ without serum separation, lithium slightly increased from that prior to being stored (Table-2).

The addition of coagulant into the vacuum collection tube expedited the processing of blood samples, enhanced assay efficiency and had been adopted clinically. This study showed that lithium in samples treated with coagulant had no significant difference with that in common serum; the serum with coagulant could replace common serum to monitor lithium for the sake of rapid assay.

This study also indicated that lithium both increased in samples treated either with heparin sodium or with coagulant, under conditions of no blood clot separation and being stored at room temperature for $8 \mathrm{~h}$. We found that the samples had to be assayed straight after collection; and in case of timely assay unavailable, serum or plasma had to be separated.

In conclusion, fixed sampling time had to be adopted to draw blood from the patients receiving chronic lithium therapy of carbonate salt and a Chinese-style breakfast had no effect on final the result. Heparin sodium anticoagulant and coagulant could be used for sample treatment, but the haemolysis had to be avoided for all types of samples. The RBC could obviously interfere with lithium result with ISE method; the whole blood sample could not be used for direct lithium assay. The blood samples had to be assayed straight after collection; otherwise, serum or plasma had to be separated. With serum separation, lithium had no significant variation after being stored at either $4{ }^{\circ} \mathrm{C}$ or room temperature for $24 \mathrm{~h}$. The blood samples treated with separation gel could not be used for lithium assay with ISEs, neither for storage nor for shipping.

The insufficiency of this research work had to be pointed out that not enough samples had been brought into our study because of a lack of research funds.

\section{ACKNOWLEDGEMENTS}

Excellent technical assistance has been provided by the personnel of Clinic Lab and Psychiatry Department at the 2nd Affiliated Hospital of Xingxiang Medical University. This study was supported by grant from the Fund for Talents with Innovation in Medical Science and Technology of Henan Province (3052) and Social Science Foundation of Hunan Province in China (12YBA323).

\section{REFERENCES}

1. H.R. Pilcher, Nature, 425, 118 (2003)

2. F.K. Goodwin, J. Clin. Psychiatry, 64, 5 (2002).

3. F.K. Goodwin, B. Fireman, G.E. Simon, E.M. Hunkeler, J. Lee and D. Revicki, JAMA, 290, 1467 (2003).

4. L.V. Kessing, L. Søndergård, K. Kvist and P.K. Andersen, Arch. Gen. Psychiatry, 62, 860 (2005).

5. A. Amdisen, Scand. J. Clin. Lab. Invest., 20, 104 (1967).

6. J. Pybus and G.N. Jr. Bowers, Clin. Chem., 16, 139 (1970).

7. N. Marque, N. Mansencal, J.F. Morisson-Castagnet and O. Dubourg, Arch. Mal. Coeur Vaiss., 97, 271 (2004).

8. R.K. Sylvester, J. Leitch and C. Granum, Pharmacotherapy, 16, 466 (1996).

9. M. Cyr, M.A. Guia and S.C. Laizure, Ann. Pharmacother, 36, 427 (2002).

10. A. Amdisen, Ther. Drug Monit., 2, 73 (1980).

11. D.B. Nevius and G.F. Lnnchantin, Clin. Chem., 11, 633 (1965).

12. J.A. Bowman, Anal. Chim. Acta, 37, 465 (1967)

13. L. Decaprio, N. Hardister, D. Macmillan, R. Welch and G. Widdowson, Clin. Chem., 33, 1668 (1987)

14. A.W. Lyon, C. Whitley and S.L. Eintracht, Ther. Drug Monit., 26, 98 (2004).

15. R.H. Christenson, J.J. Mandichak, S.H. Duh, J.M. Augustyn and J.C. Thompson, Clin. Chim. Acta, 327, 157 (2003).

16. J.D. Gorham, K.G. Walton, A.C. Mcclellan and M.G. Scott, Ther. Drug Monit., 16, 277 (1994).

17. M.F. Teixeira, F.C. Moraes, E.T. Cavalheiro and N. Bocchi, J. Pharm. Biomed. Anal., 31, 537 (2003).

18. B. Leboulanger, J.M. Aubry, G. Bondolfi, R.H. Guy and M.B. DelgadoCharro, Clin. Chem., 50, 2091 (2004).

19. E. Pierson, K. Luterbach, E. Rzepka and S. Ramaprasad, Magn. Reson. Imaging, 22, 123 (2004).

20. E.X. Vrouwe, R. Luttge, I. Vermes and A. van Den Berg, Clin. Chem., 53, 117 (2007).

21. S.E. Dufresne, B. Boulerice and R. Elie, J. Psychiatry Neurosci., 26, 330 (2001)

22. M. Sampson, M. Ruddel and J. Ronald, Clin. Chem., 40, 869 (1994).

23. A.O. Okorodudu, R.W. Burnett, R.B. Mccomb and G.N. Bowers Jr., Clin. Chem., 36, 104 (1990).

24. P. Bonini, M. Plebani, F. Ceriotti and F. Rubboli, Clin. Chem., 48, 691 (2002).

25. S. Narayanan, Am. J. Clin. Pathol., 113, 429 (2000).

26. M. Sampson, M. Ruddel, S. Albright and R.J. Elin, Clin. Chem., 43, 675 (1997).

27. J. Greffe and B. Gouget, Scand. J. Clin. Lab. Invest., 224, 187 (1996).

28. X.S. Guo, W.F. Wang and C.G. Zhang, Shanghai J. Med Lab. Sic., 14, 244 (1999).

29. M.W. Linder and P.E. Keck, Clin. Chem., 44, 1073 (1998).

30. M. Camus, É.G. Henner, G. Baron, G. Peytavin, L. Massias, F. Mentré and R. Farinotti, Eur. J. Clin. Pharmacol., 59, 583 (2003).

31. J.C. Mathies, Clin. Chem., 20, 1573 (1974)

32. R.A. Bowen, Y. Chan, J. Cohen, N.N. Rehak, G.L. Hortin, G. Csako and A.T. Remaley, Clin. Chem., 51, 424 (2005).

33. R.A. Bowen, Y. Chan, M.E. Ruddel, G.L. Hortin, G. Csako, S.J. Demosky Jr, and A.T. Remaley, Clin. Chem., 51, 1874 (2005). 